American Journal of Agricultural and Biological Sciences 6 (4): 536-543, 2011

ISSN 1557-4989

(C) 2011 Science Publications

\title{
Influence of Host Plant Species and Flush Growth Stage on the Asian Citrus Psyllid, Diaphorina citri Kuwayama
}

\author{
${ }^{1}$ Stephen Leong Chan Teck, ${ }^{2}$ Abang Fatimah, ${ }^{3}$ Andrew Beattie, \\ ${ }^{1}$ Roland Kueh Jui Heng and ${ }^{1}$ Wong Sing King \\ ${ }^{1}$ Department of Crop Science, \\ Faculty of Agriculture and Food Sciences, \\ University Putra Malaysia Bintulu Sarawak Campus, \\ 97008 Bintulu, Sarawak, Malaysia \\ ${ }^{2}$ Department of Zoology, \\ Faculty of Resource Science and Technology, \\ University Malaysia Sarawak, 94300 Kota Samarahan, Sarawak, Malaysia \\ ${ }^{3}$ Centre for Plant and Food Science, University of Western Sydney, \\ Locked Bag 1797, Penrith South DC, New South Wales, 1797, Australia
}

\begin{abstract}
Problem statement: In order to establish the important host range of $D$. citri, the performance of this psyllid on different rutacous host plants was assessed. Apparent regional differences in host preferences of $D$. citri as noted above and the need for empirical knowledge of its host preferences in Malaysia where it is lacking. Approach: Experiments on host plant preference between citrus, jasmine orange and curry leaf were conducted over a period of 14 days in the field cage in October 1998 at the agricultural research centre, Semonggok, $15 \mathrm{~km}$ from Kuching, Kuching Division, Sarawak in Malaysia. Results: A comparative life cycle study of the Asian Citrus Psyllid Diaphorina citri Kuwayama on three different Rutaceous plant hosts namely citrus, jasmine orange and curry leaf plants was conducted inside the temperature controlled growth chamber maintain at $26 \pm$ $1^{\circ} \mathrm{C}$ temperature, $75-80 \%$ relative humidity with artificial illumination intensity of 10,000 lux equipped with a photoperiod of $14: 10 \mathrm{~h}$ light: dark regime to permit normal growth. Conclusion: The screenhouse studies confirmed that $D$. citri can colonise and breed on citrus, jasmine orange and curry leaf plant and that jasmine orange is the preferred host. It is also confirmed that females prefer to oviposit on immature flush 3-10 mm in length. In growth chamber experiments the life cycle of the psyllid was 18.5 days on jasmine orange, 19.0 days on citrus and 23.0 days on curry leaf.
\end{abstract}

Key words: Diaphorina citri, flush growth stage, life cycle, Analysis Of Variance (ANOVA), Least Significant Difference test (LSD), M. paniculata, B. koenigii, Clausena anisum-olens, Asian citrus psyllid, host plant, nymphal development, hypothesis

\section{INTRODUCTION}

Psyllids are generally narrowly host specific and restricted almost exclusively to perennial dicotyledenous plants (Eastop, 1972). The mechanism of host-plant selection is probably chemo-gustatory (Hodkinson, 1974). The phytophagous nymphs and adults of $D$. citri are reported to feed and breed on species of Citrus (which now include Eremocitrus, Fortunella, Microcitrus and Poncirus), Atalantia, B. koenigii, Clausena, Merrillia, M. paniculata, Swinglea, Triphasia, Toddalia and Vepris (Ayyar, 1963; Chakraborty et al., 1976; Aubert, 1990; Waterhouse,
1998). The relative suitability of its various host plants is probably due to a combination of factors: e.g. different $D$. citri biotypes, host plant phenoype and the impact of environmental factors on canopies and host plant phenology.

Aubert (1990) reported that D. citri populations in Malaysia breed well on $B$. koenigii, in contrast to observations in Réunion and in the Philippines, adults are more attracted by Clausena anisum-olens (Blanco) Merrill than to M. paniculata. Overall, M. paniculata, a widely cultivated ornamental shrub and hedge plant in Southern and Southeast Asia, is considered to be the preferred host (Waterhouse, 1998). Dispersal of high

Corresponding Author: Stephen Leong Chan Teck, Department of Crop Science, Faculty of Agriculture and Food Sciences, University Putra Malaysia Bintulu Sarawak Campus, 97008 Bintulu, Sarawak, Malaysia 
populations of infectious adult $D$. citri from alternative hosts adjacent to citrus orchards has resulted in transmission of HLB and subsequent severe reductions in yield of citrus fruits, even though adults are weak fliers and dispersal is largely governed by wind speed and direction (Aubert, 1990). Seasonal movement between alternative hosts allows the psyllid to exploit a continuous supply of nutritionally favorable foliage and oviposition sites (Hughes et al., 1970; Catling, 1969a; Moran, 1968). Egg-laying is strongly influenced by the availability of new growth flush and breeding is largely suspended when trees become dormant. Eggs are laid exclusively on tender young flush points and nymphs develop on immature leaves (Catling, 1969a; Waterhouse, 1998).

In order to establish the important host range of $D$. citri, the performance of this psyllid on different Rutacous host plants was assessed. Apparent regional differences in host preferences of $D$. citri as noted above and the need for empirical knowledge of its host preferences in Malaysia, has led to study its preferences and biology on three common hosts in Sarawak: $C$. reticulata, $M$. paniculata and $B$. koenigii. The hypothesis was that $M$. paniculata as a preferred host and $B$. koenigii as a significant alternative host and adult female psyllids prefer to settle and oviposit on the new growth flush. The objectives of these two experiments are, first to determine the preferred host for oviposition and the duration of the egg and nymphal stage in the life cycle of D. citri on the three hosts and second to determine the specific characteristics of flush growth chosen for oviposition by adult female psyllids.

\section{MATERIALS AND METHODS}

Plant house and cage studies: The plant house $(16.2 \mathrm{~m}$ long, $9 \mathrm{~m}$ wide with a $3 \mathrm{~m}$ high roof) used in the experiments was located at the Agricultural Research Centre, Semongok, $15 \mathrm{~km}$ from Kuching, Kuching Division, Sarawak in Malaysia. The plant house was partitioned into three large screened enclosures, each 5.4 long, $3 \mathrm{~m}$ wide. A small cage $(0.56 \mathrm{~m}$ long, $0.56 \mathrm{~m}$ wide with $0.74 \mathrm{~m}$ high) located outside the plant house was used for oviposition studies.

Adult female psyllids used in the experiments were collected on the day they were required from cultures maintained on either the potted jasmine orange $M$. paniculata plants kept inside a temperature controlled growth chamber maintained at $25-28^{\circ} \mathrm{C}$ or from plants kept in the plant house, or from $M$. paniculata hedges in Kuching. They were collected by aspirating adults from foliage with a mouth aspirator and then transferred into a rearing cage $(210 \mathrm{~mm}$ long, $235 \mathrm{~mm}$ wide, $285 \mathrm{~mm}$ high) until released onto plants used in experiments.
Host plant preference: Experiments on host plant preference between citrus, jasmine orange and curry leaf were conducted over a period of 14 days in the field cage in October 1998 at the Agricultural Research Centre, Semonggok, Kuching. One week beforehand, potted plants of these three different plant hosts were lightly pruned, fertilized, watered and placed in 5 rows on the bench in a large screen cage $(5.4 \times 3 \times 3 \mathrm{~m}$ with $1 \mathrm{~mm}$ mesh) to encourage new growth. At the end of the week, a total of 10 one-year-old plants per replicate of each plant species were selected on the basis of similar flushing characteristics. These plants were then arranged in a randomized block design with ten replications, about $30 \mathrm{~cm}$ apart to ensure that their canopies did not touch in the plant house. On the same day $350 \mathrm{D}$. citri adult females, collected from cultures maintained on $M$. paniculata, were released as evenly as possible above the plants in the cage. The number of adults settled on the seedlings and eggs oviposited on the plants were counted and recorded daily. The observations were made at 10:00 am daily and each plant took approximately 2 min per observation. The eggs were removed after counting.

Twenty flushes of different length $(1-15 \mathrm{~mm})$ per replicate were observed randomly on each plant species each day for 14 days and daily numbers of adult females, eggs and first and second instar nymphs were counted and recorded. A 10x handlens was used to count eggs. Counts were averaged per plant. These data were subjected to one-way Analysis Of Variance (ANOVA). All means were separated using the Least Significant Difference test (LSD).

Comparative life cycle of $\boldsymbol{D}$. citri: A comparative life cycle studies on relatively uniform seedlings of the three hosts between citrus, jasmine orange and curry leaf plants were conducted in a temperature controlled growth chamber maintained at $26 \pm 1^{\circ} \mathrm{C}, 75-80 \%$ relative humidity with artificial illumination (10,000 lux) on a photoperiod of 14:10 (L:D) regime to permit normal growth. One each of one year old seedlings of citrus (30 $-35 \mathrm{~cm}$ tall), jasmine orange and curry leaf (both are about $30 \mathrm{~cm}$ tall) was placed inside the growth chamber $(16 \times 16 \times 130 \mathrm{~cm})$. Two hundred adult psyllids (consisting 100 each of male and female) from maintained stock colonies were released for egg laying in a cage $(0.56 \times 0.56 \times 0.74 \mathrm{~m})$ where a group of 10 seedlings of each species were placed for oviposition over a period of $24 \mathrm{~h}$. At the end of this period, the adults were removed and plants with eggs were checked and counted under a stereomicroscope. Only eggs that were laid within $24 \mathrm{~h}$ were used. After egg hatching, at least 10 first-instar nymphs collected were transferred individually to each seedling of each test species using 
a camel hair brush. A total of 300 first-instar nymphs were used for this study. A total of ten 1 year old seedlings (replicates) of each species were used and arranged randomly in the experiment. Twenty flushes of different length $(1-15 \mathrm{~mm})$ per replicate were observed randomly on each plant species each day for 14 days and daily numbers of adult females, eggs and first and second instar nymphs were counted and recorded. A 10x handlens was used to count eggs. The number of eggs oviposited on the host plants were collected and recorded daily. The rate of development (the duration of each instar) were determined daily at 10:00 am. In this study, the development of the immature stages of D. citri on three different hosts was used as a criterion of host plant suitability. Counts were averaged per plant. These data were subjected to one-way Analysis Of Variance (ANOVA). All means were separated using the Least Significant Difference test (LSD).

Data are presented on the instar nymph duration and the mortalities of the immature nymphal stages of D. citri on the different hosts. Observations were recorded every day on the mortality of instar nymphs. A loss was recorded when the insects were not found and were presumed to have dropped off the plant and died, a death was recorded when the corpse of the psyllid nymph was found shrivelled on the leaf.

Influence of flush growth stage of citrus on oviposition behavior of $\boldsymbol{D}$. citri: This experiment was conducted in November 1998 at Agricultural Research Centre, Semonggok, Kuching. Two-year old potted langkat mandarin trees were used in these studies, they were lightly pruned to a uniform canopy size, fertilized and watered once daily and then placed in a screen enclosured cage $(5 \times 3 \times 3 \mathrm{~m})$ in the plant house to encourage new growth one week before experiments commenced. Thirty plants with a similar flush growth patterns were chosen for the experiment and arranged in a randomised block design with ten replications, about $10 \mathrm{~cm}$ between plants in the cage. Two hundred adult females collected from maintained stock colonies on $M$. paniculata were then released into the cage. After flushing resumed 4 days later, the numbers of adult settled on the seedlings were counted. The numbers of eggs laid were counted daily on up to 20 randomly chosen flushes on each plant over an interval of 1 day for 14 days and the length of each of these flushes was measured on each occasion. A total of 688 flush samples were collected and these flushes were categorised as different age group with corresponding flush length as follows :- $<3 \mathrm{~mm}$ (1-4 d old), 3-6 mm (5-7 d old), 7-10 mm (8-10 d old) and > $10 \mathrm{~mm} \mathrm{(>10} \mathrm{d}$ old).
Data analysis: Data were analyzed by calculating means, standard error of means and by performing oneway Analysis Of Variance (ANOVA). All means were separated using the Fisher's Least Significant Difference test (LSD) after a F-test is significant ( $\mathrm{p} \leq$ $0.05)$.

\section{RESULTS}

Host plant preference: The result (Table 1) confirmed that $D$. citri can colonise and breed on the three host species tested. However, there were significant differences $(\mathrm{F} 4,8=1.44, \mathrm{~F} 4,8=1.34, \mathrm{~F} 4,8=5.75 ; \mathrm{P}$ $\leq 0.05$ ) between mean numbers of adults, eggs and nymphs recorded on each of these hosts. Numbers of psyllid were significantly higher on $M$. paniculata than on $C$. reticulata and significantly higher on the latter than on B. koenigii. The result showed that D. citri adult females preferred to settle on $M$. paniculata than $C$. reticulata and $B$. koenigii for oviposition. The average number of egg produced by the female psyllid was higher on $M$. paniculata (77.4 eggs), followed by B. koenigii (48.8 eggs) and C. reticulata (26.4 eggs).

Comparative life cycle of $\boldsymbol{D}$. citri: In this study, the development of the immature stages of $D$. citri on $C$. reticulata, $M$. paniculata and $B$. koenigii is used as a criterion of host plant suitability. The development for egg and nymph in the life cycle of $D$. citri are presented in Table 2. The mean incubation period for egg was not significantly different, ranging from 3.0-4.0 days (Table $2 ; \mathrm{p}=0.05)$ on $C$. reticulata, B. koenigii and $M$. paniculata respectively. The average duration of the nymphal stages was significantly different (F 2,6 = $31.5 ; \mathrm{p} \leq 0.001)$ and recorded at $14.5,16.0$ and 19.0 days on $M$. paniculata, $C$. reticulata and $B$. koenigii respectively. There were significant differences ( $F$ $2,6=24.33 ; \mathrm{p} \leq 0.001)$ between the mean duration from egg to adult stage on each of these hosts.

Table 1: Mean Number of D Citri Adults, Eggs and Nymphs on Jasmine Orange, Citrus and Curry Leaf plants after Release of Psyllid in the plant house

\begin{tabular}{llll}
\hline & $\begin{array}{l}\text { Mean nos adult } \\
\text { psyllid alighted } \\
\text { per flush }\end{array}$ & $\begin{array}{l}\text { Mean nos. } \\
\text { eggs } \\
\text { per plant }\end{array}$ & $\begin{array}{l}\text { Mean nos. } \\
\text { nymphs } \\
\text { per plant }\end{array}$ \\
\hline Jasmine Orange & $15.25 \pm 0.18^{\mathrm{a}}$ & $77.4 \pm 0.3^{\mathrm{a}}$ & $62.9 \pm 0.56^{\mathrm{a}}$ \\
Citrus & $9.28 \pm 0.16^{\mathrm{b}}$ & $26.4 \pm 0.26^{\mathrm{b}}$ & $15.0 \pm 0.38^{\mathrm{b}}$ \\
Curry Leaf & $3.77 \pm 0.08^{\mathrm{c}}$ & $48.8 \pm 0.12^{\mathrm{c}}$ & $46.7 \pm 0.48^{\mathrm{a}}$ \\
SE (difference) & 1.75 & 3.25 & \\
CV $(\%)$ & 18.50 & 25.80 & \\
\hline
\end{tabular}

Means in a column not followed by the same letter are significantly different at $\mathrm{p} \leq 0.05$ by Least Significant Test. Data based on square root transformation prior to ANOVA 
Am. J. Agri. \& Biol. Sci., 6 (4): 536-543, 2011

Table 2: Mean egg hatch and developmental periods (days) of immature stages of D. citri on three host plants at $26^{\circ} \mathrm{C}$

\begin{tabular}{|c|c|c|c|}
\hline \multirow[b]{2}{*}{ Host plant } & \multicolumn{3}{|c|}{ Life stage of $D$. citri (mean \pm S.E.) } \\
\hline & Egg stage & $\begin{array}{l}\text { Total of } \\
\text { nymphal stage }\end{array}$ & $\begin{array}{l}\text { From egg } \\
\text { to adult }\end{array}$ \\
\hline Citrus & $3.00 \pm 0.09^{\mathrm{a}}$ & $16.0 \pm 0.10^{\mathrm{a}}$ & $19.0 \pm 0.19^{\mathrm{a}}$ \\
\hline Jasmine Orange & $4.00 \pm 0.07^{\mathrm{a}}$ & $14.5 \pm 0.15^{\mathrm{b}}$ & $18.5 \pm 0.22^{\mathrm{a}}$ \\
\hline Curry Leaf & $4.00 \pm 0.08^{\mathrm{a}}$ & $19.0 \pm 0.12^{\mathrm{a}}$ & $23.0 \pm 0.20^{\mathrm{b}}$ \\
\hline SE (difference) & 0.47 & 0.81 & 1.0 \\
\hline $\mathrm{CV}(\%)$ & 12.90 & 4.90 & 5.0 \\
\hline
\end{tabular}

Means in a column not followed by the same letter are significantly different at $\mathrm{p} \leq 0.05$ by Fisher's Least Significant Test.

Table 3: Percentage losses, deaths and survival recorded for nymphs of $D$. citri on three different host plants

\begin{tabular}{lllll}
\hline & $\begin{array}{l}\text { No. of } \\
\text { Readings }\end{array}$ & $\begin{array}{l}\text { Losses } \\
(\%)\end{array}$ & $\begin{array}{l}\text { Deaths } \\
(\%)\end{array}$ & $\begin{array}{l}\text { Survival } \\
(\%)\end{array}$ \\
\hline Citrus & 20 & $20^{\mathrm{a}}$ & $20^{\mathrm{a}}$ & $60^{\mathrm{a}}$ \\
Jasmine orange & 20 & $20^{\mathrm{a}}$ & $10^{\mathrm{a}}$ & $70^{\mathrm{a}}$ \\
Curry leaf & 20 & $30^{\mathrm{a}}$ & $20^{\mathrm{a}}$ & $50^{\mathrm{a}}$ \\
\hline
\end{tabular}

Means in a column not followed by the same letter are significantly different at $\mathrm{p} \leq 0.05$ by Least Significant Difference test

The results showed that the vector completes its life cycle (from egg to adult) in shortest period (18.5 days) on M. paniculata, followed by C. reticulata (19.0 days) and B. koenigii (23.0 days).

None of the data on the nymphal mortalities and survival of $D$. citri on different plants were significantly different as presented on Table 3. The percentages of losses and deaths recorded indicated the suitability of the different plants as hosts to $D$. citri. The greatest number of losses was recorded for nymphs reared on citrus, followed by Jasmine orange. The percentage of survival recorded for the immature stage of $D$. citri on M. paniculata $(70 \%)$ was very high, as compared with $50 \%$ survival on B. koenigii and $60 \%$ survival recorded on $C$. reticulata.

Influence of flush growth stage of citrus on oviposition behavior by $D$. citri: Flush growth was first noticed 4 days after adult $D$. citri were released into the cage containing the plants. Figure 1 and Table 4 show the distribution of adult female settling and ovipositing on various flush growth stages. Psyllid females showed a significant preference for younger flushes especially between 3-6 mm long for oviposition $\left(\chi^{2}=31.78^{* *}, 9 \mathrm{df} ; \mathrm{p} \leq 0.05\right)$. The result shows that almost half $(49.5 \%)$ of the eggs were laid on the 3-6 $\mathrm{mm}$ long young flushes, while $36.8 \%$ were found on 7 $10 \mathrm{~mm}$ long flushes. Less than $20 \%$ of females and less than $15 \%$ of eggs were observed on shorter and longer flushes respectively. Settlement and oviposition on 2-6 $\mathrm{mm}$ long flushes were greater than on 7-10 $\mathrm{mm}$ long flushes (Table 4). Under plant house condition, the results indicate that the most preferred new growth flushes for oviposition by female psyllids was 4-7 days old flushes between 3-10 mm long.
Table 4: Oviposition (percentage eggs per female) and Visitation by

\begin{tabular}{lcc}
\multicolumn{2}{c}{ D. citri females } \\
\hline Flush length (mm) & Adult alighted $(\%)$ & Egg laid $(\%)$ \\
\hline 2 & 3.33 & 1.89 \\
6-Mar & 44.21 & 49.53 \\
10-Jul & 32.97 & 36.79 \\
$>10$ & 19.49 & 11.79 \\
\hline
\end{tabular}

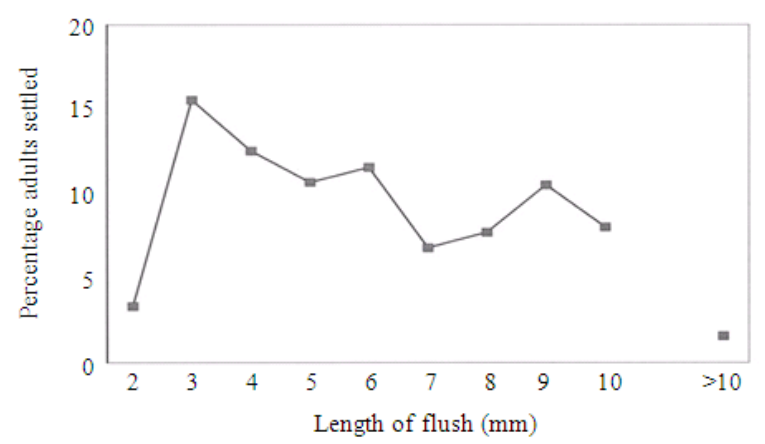

Fig. 1:Distribution of D. citri on citrus flushes of different stages of growth

\section{DISCUSSION}

Host plant preference: In current study, the results show that $D$. citri can breed on the three host species tested and the mean numbers of adult, egg and nymph were significantly higher on $M$. paniculata than $C$. reticulata and $B$. koenigii. Therefore, D. citri adult females preferred to settle on $M$. paniculata than $C$. reticulata and B. koenigii for oviposition. D. citri has a restricted host range including citrus species and related members of the Rutaceae (Mead, 1977). Not much on host comparison study has been reported. Halbert and Manjunath (2004) report that the host range of D. citri includes 25 genera in the family Rutaceae, although not all of these are good hosts. The present results confirmed earlier observations by Aubert (1987) who reported that $M$. paniculata was the preferred host of 21 host species/cultivars he tested as hosts of D. citri and Osman and Quilici (1991) in a survery observed that $M$. paniculata, B. Koenigii, C. Reticulata, limau purut ( $C$. hystrix), limau kesturi or calamondin (C. microcarp) and Clausena excavata Burm.f. were the alternate hosts for D.citri in Malaysia. Due to limited resources, it was unable to compare all recorded and possible hosts of $D$. citri. Although the report by Aubert (1990) from the Philippines and R'eunion that D. citri prefers Clausena anisum-olens to M. paniculata could not be verified, the results reported here were able to demonstrate that $D$. citri will breed well on B. koenigii. The results (Table 1) also confirmed that citrus species and Murraya paniculata are a preferred host plant as has been reported by Catling (1969a) and Waterhouse (1998) and 
the D. citri populations breeding on Murraya and Citrus are closely correlated with flushing, as eggs were laid exclusively on very young flush points and nymphs developed on immature leaves. Oviposition preference is essentially important in insects such as psyllids because mobile adults must find host plants for their relatively immobile offspring. The reason for the higher oviposition rate (Table 1) on $M$. paniculata could be the result of physical factors of the jasmine orange plant or physiological factors such as leaf hardness (Moran, 1968; Moran and Buchan,1975) and D. citri females prefer soft leaves for oviposition (Berg et al., 1991). Contact with host foliage appears to be critical for stimulation of oviposition. Traynier (1979) and Renwick and Radke (1983) showed that tarsal contact provided the necessary stimulus and the presence of non-volatile chemical stimulants such as the flucosinolates could be responsible for host recognition and stimulation of oviposition by ovipositing $D$. citri females upon landing.

Catling (1970) noted that heavy and prolonged flushing of young host plants has made them very attractive to the psyllid. Chakraborty et al. (1976) reported that psyllid adults preferred B. koenigii to citrus during adverse climatic conditions but again return to citrus trees when the ecological conditions are favourable. This preference and the overall preference for $M$. paniculata, which is widely grown in the tropics and subtropics as an ornamental shrub and hedge plant flushed almost continuously, may be predominantly related to the extent and frequency of flushing. The continuous flushes produced by. M. paniculata could play an important role in maintaining high populations of this vector when new flushes are not available in citrus. It may probably serve as important reservoirs of vectors because of their more frequent flushes of new growth year round make them 'attractive' to the insect vector. Citrus being the main host plant, successful breeding of the vector on non-citrus hosts such as $M$. paniculata and $M$. koenigii warrants a situation where such plants can act as dangerous reservoir of psyllids. This finding can be used in controlling the psyllids when they are absent on citrus trees but remain on jasmine orange or curry leaf plants. Control measures with suitable insecticides on these alternate hosts and also on citrus trees may help in eliminating the psyllids and thereby check the spread of greening disease by the vector. Although feeding, nutrition and the chemotactic basis for host plant selection have been extensively investigated in a closely related family, the Aphidae (Auclair, 1963; Kennedy et al., 1961), nothing is known about host choice in the Psyllidae. The lack of response of the psyllids to chemical extracts may be an indication that nutritive factors in the leaves play a role in host plant selection (Gerling, 1990) in this species. The mechanism of host plant selection by adult psyllids is unknown, but is most probably chemo-gustatory as reported by Hodkinson (1974).

Comparative life cycle of $\boldsymbol{D}$. citri: The results showed that host plants had some effects on the development and survival/mortality of $D$. citri (Table 2 and 3 ). It is generally believed that shorter developmental times and greater total reproduction on a host plant reflect the suitability of the plant tested (Gerling, 1990). D. citri reared on $M$. paniculata showed a higher oviposition rate, a faster development and lower mortality (Table 1$3)$. Therefore, this host is more suitable for D. citri. In this study at $26^{\circ} \mathrm{C} \mathrm{D}$. citri completed its life cycle in shortest duration on $M$. paniculata, than $C$. reticulata and most slowly on B. koenigii. Thus D. citri can produce more generations on $M$. paniculata than on other host plants. These results indicate that $M$. paniculata was most suitable for the development of $D$. citri. D. citri also develops very adequately on $C$. reticulata and $B$. koenigii and must have been well preadapted to these hosts. This suggest that the outcome of this test accepts the hypothesis that $M$. paniculata as a preferred host plant for $D$. citri and was most suitable for the development of immature psyllid nymphs.

The results are similar to those recorded by other authors (Chakraborty et al., 1976; Tsai and Liu, 2000). The present results show that at $26^{\circ} \mathrm{C}$ the average egg incubation period on the tested hosts was 3.0, 4.0 and 4.0 days and the mean nymphal developmental periods were $14.5,16.0$ and 19.0 days and the total life cycle required from 18.5-23.0 days for $M$. paniculata, $C$. reticulata and $B$. koenigii respectively. While $M$. koenigii is reported as favourable host plant for $D$. citri (Chakraborty et al., 1976). The present findings indicate that its life cycle is slower on this host. So far, not much information is available on the comparative life cycle of psyllid on citrus and other rutaceous plant species, but it has been pointed out that duration of life stages of $D$. citri depends on seasons, with adult stage as long as 190 days in winter and only 20 days in summer. The results show that the mean egg incubation period is shorter than the 4-20 day reported by Pruthi (1945). Catling (1970) reported that an average egg incubation period of 3 days was required at a mean temperature of $25-26^{\circ} \mathrm{C}$ and that nymphal development was completed in 11-15 days. Pande (1971) reported that nymphal development periods of $D$. citri varied from 10-30 days depending on the season. Mead (1977) stated that total life cycle in Florida required from 15 to 47 days depending upon the season and adult may live 
for several months. These variations may due to these observations were made at different temperatures and host species.

Chakravarthi et al. (1998) reported that D. citri at maximum temperature of $30.5^{\circ} \mathrm{C}$ and minimum temperature of $17.0^{\circ} \mathrm{C}$ had a highest rate of fecundity and fastest development of nymphs on B. koenigii when compared to acid lime (C. aurantiifolia) and sweet orange ( $C$. aurantium). Among these, the first was the preferred host and on it the duration of the nymphal stages (8.6 days) and life cycle (12.4 days) of D. citri were shorter than in this study. Liu and Tsai (2000) reported that $D$. citri reared at $25^{\circ} \mathrm{C}$ on $M$. paniculata had a longer egg incubation period (4.2 days) and a shorter total nymphal development period (12.8 days) than in this study and at $15^{\circ} \mathrm{C}$ development from egg to adult took 49.3 day compare to 17 day at $25^{\circ} \mathrm{C}$. A nymphal development period of 15 days at $25^{\circ} \mathrm{C}$ was reported by Tang and Su (1984) from Taiwan. Xu et al. (1994) reported that it took 53-59 days in spring (at an average temperature of $\left.19.6^{\circ} \mathrm{C}\right), 18-22$ days in summer $\left(28^{\circ} \mathrm{C}\right)$ and $25-30$ days in the autumn $\left(24^{\circ} \mathrm{C}\right)$ to complete a generation on citrus in Fujian, China.

The results (Table 3) show that the nymphal mortalities of $D$. citri was low $(23.4 \%)$ on $M$. paniculata, as compared with $C$. reticulata $(40 \%)$ and B. koenigii (41.2\%). This may be due to nutritional differences in the host plants and M. paniculata was more suitable for the development of $D$. citri nymphs.

These influences of temperature are clear. However, rates of development are also influenced by other factors. Psyllid development rates and the length of life cycle are related to the nutritive status of the host plant and changes in quality of plant sap, particularly changes in amino acid concentration can quickly affect psyllid development (Hodkinson, 1974). Furthermore, there is evidence that younger, more vigorous plants, perhaps with higher nitrogen contents, support higher psyllid populations than older plants (Catling, 1969b; Watmough, 1968). Catling (1971) reported that nitrogen content of young flush declined with age and in the flush of seedlings and young trees has higher nitrogen than in flush of mature trees. He further stated that the egg-laying of the psyllid female was largely controlled by the protein content of foliage. Increase in soluble nitrogen sources in plant tissues may be associated with flushing of new growth (Catling, 1971; Liu and Tsai, 2000) both enhances nymphal survival and growth rates. The condition and nutritional status of the young host plant influence nymphal development and probably the reproductive rate of female psyllids as reported by Catling (1971). Nymphs on young foliage in poor condition may be smaller, undergo prolonged development and suffer high mortality. Similar outcomes occur when nymphs develop on less-favored alternate host plants (Moran, 1968). In aphids amino acid concentrations are known to influence growth and reproduction (Auclair, 1969). It is very probable that the immature stages may have high demands for protein and that protein starvation contributed to the nymphal mortality. It is inferred that the hosts species having soft and succulent leaves made them more attractive to the psyllid while the thick and coarse or hairy and waxy leaves made them less attractive.

Influence of flush growth stage of Citrus on oviposition behavior by $D$. citri: On $C$. reticulata, flushes 3-10 mm long were preferred for oviposition as $85 \%$ of eggs were laid on growth within this range. Clearly, this choice is made so as for nymphal development, flushes longer than $10 \mathrm{~mm}$ were far less suitable. This suggest that the females only oviposited on the tender flushes and showed a higher preference for younger flush growth especially between 3-6 mm long. In the absence of suitable tissue, the oviposition may cease temporarily as reported by Tsai and Liu (2000). The preference of the females to oviposit on the $3-10 \mathrm{~mm}$ young flushes was expected as oviposition is triggered by the presence of young flushes (Catling, 1969a). This suggest that the outcome of this test accept the hypothesis that the most preferred age of citrus flush for oviposition was four to seven day old with flush length between 3-10 $\mathrm{mm}$. Although this suggest that spray programs for control of the psyllid would benefit from such a narrow opportunity for oviposition within trees and between trees in citrus groves can be quite variable. However, the results suggest that such spray programs should commence as soon as outbreak is observed in an orchard and continue until all flushes are longer than $25 \mathrm{~mm}$.

\section{CONCLUSION}

The screenhouse studies confirmed that D.citri can colonise and breed on citrus, jasmine orange and curry leaf plant and that jasmine orange is the preferred host. It was also confirmed that females prefer to oviposit on immature flush 3-10 $\mathrm{mm}$ in length. In growth chamber experiments the life cycle of the psyllid was 18.5 days on jasmine orange, 19.0 days on citrus and 23.0 days on curry leaf. 


\section{REFERENCES}

Aubert, B., 1987. Trioza erytheae del Guercio and Diaphorina citri Kuwayama (Homoptera: Psylloidea), the two vectors of citrus greening disease: Biological aspects and possible control stratégies. Fruits, 42: 149-162.

Aubert, B., 1990. Integrated Activities for the Control of Huanglongbing-Greening and its Vector Diaphorina citri Kuwayama in Asia. Proceedings of the 4th International Asia-Pacific Conference on Citrus Rehabilitation, Feb. 4-10, UNDP-FAO, Chiang Mai, Thailand, pp: 133-144.

Auclair, J.L., 1963. Aphid feeding and nutrition. Ann. Rev. Entomol., 8: 439-490. DOI: 10.1146/annurev.en.08.010163.002255

Auclair, J.L., 1969. Nutrition of plant-sucking insects on chemically defined diets. Entomol. Exp. Appli., 12: $\quad 623-641$. DOI: $\quad 10.1111 / \mathrm{j} .1570-$ 7458.1969.tb02558.x

Ayyar, T.V.R., 1963. Handbook of Economic Entomology for South India. 1st Edn., Printed by the Controller of Stationery and Print., Madras, on behalf of the Govt. of Madras, Madras, pp: 516.

Catling, H.D., 1969a. The bionomics of the South African citrus psylla, Trioza erytreae (Del Guercio) (Homoptera: Psyllidae). Sth Afric. Citrus J.

Catling, H.D., 1969b. The bionomics of the South African citrus psylla, Trioza erytreae (Del Guercio) (Homoptera: Psyllidae). 1. The influence of the flushing rhythm of citrus and factors which regulate flushing. J. Ent. Soc. Sth. Afr., 32: 191-208.

Catling, H.D., 1970. The bionomics of the South African citrus psylla Trioza erytreae (Del Guercio) (Hornoptera: Psyl 1 idae) 4. The influence of predators. 4. The influence of predators. J. Ent. Soc. Sth. Afr., 33: 341-349.

Catling, H.D., 1971. The bionomics of the South African citrus psylla, Trioza erytreae 5. The influence of host plant quality. J. Ent. Soc. Sth Afr., 34: 381-391.

Chakraborty, N.K., P.K. Pandey, S.N. Charterjee and A.B. Singh, 1976. Host preference in Diaphorina citri Kuwayama, vector of greening disease of citrus in India. Ind. J. Entomol., 38: 196-197.

Chakravarthi, V.P., P. Savithri, P.R. Prasad and N.V. Rao, 1998. Biology and seasonal abundance of citrus psylla, Diaphorina citri Kuwayama (Homoptera: Psyllidae). Proceeding of the 1st National Symposium Pest Management Hort, (PMH' 98), Crops, Bangalore, pp: 32-33.
Berg, M.A.V.D., V.E. Deacon and P.J. Steenekamp, 1991. Dispersal within and between citrus orchards and native hosts and nymphal mortality of citrus psylla, Trioza erytreae (Hemiptera: Triozidae). Agric., Ecosyst. Environ., 35: 297-309. DOI: 10.1016/0167-8809(91)90080-H

Eastop, V.F., 1972. Deductions from the present day host plants of aphids and related insects. Symp. Roy. Ent. Soc. Lond., 6: 157-178.

Gerling, D., 1990. Whiteflies: Their Bionomics, Pest Status and Management. 1st Edn., Intercept, Andover, Hants., UK., ISBN: 0946707162, pp: 348.

Halbert, S.E. and K.L. Manjunath, 2004. Asian citrus psyllids (Sternorrhyncha: Psyllidae) and greening disease in citrus: A literature review and assessment of risk in Florida. Florida Entomol., 87: 330-353.

Hodkinson, I.D., 1974. The biology of the Psylloidea (Homoptera): A review. Bull. Entomol. Res., 64: 325-338. DOI: $10.1017 /$ S0007485300031217

Hughes, R.D., L.R. Clark and P.W. Geier, 1970. The Ecology of Insect Populations in Theory and Practice. 1st Edn., Methuen, London, pp: 232.

Kennedy, J.S., C.O. Booth and W.J.S. Kershaw, 1961. Host finding by aphids in the field. III. Visual attraction. Ann. Applied Biol., 49: 1-21. DOI: 10.1111/j.1744-7348.1961.tb03587.x

Liu, Y.H. and J.H. Tsai, 2000. Effects of temperature on biology and life table parameters of the Asian citrus psyllid, Diaphorina citri Kuwayama (Homoptera: Psyllidae). Ann. Applied Biol., 137: 201-206. $\quad$ DOI: $\quad 10.1111 / \mathrm{j} .1744-$ 7348.2000.tb00060.x

Mead, F.W., 1977. The Asiatic citrus psyllid, Diaphorina citri Kuwayama (Homoptera: Psyllidae). Florida Dept. Agric. Cons. Serv., Div.

Moran, V.C. and P.R. Buchan, 1975. Oviposition by the citrus psylla, Trioza erytreae (Homoptera: Psyllidae), in relation to leaf hardness. Entomol. Expt. Appli., 18: 96-104. DOI: 10.1111/j.15707458.1975.tb00390.x

Moran, V.C., 1968. The development of the citrus psylla, Trioza erytreae (Del Guercio) (Hornoptera: Psyllidae), on Citrus limon and four indigenous host plants. Cut. Soc. Sth. Afr., 31: 391-402.

Osman, M.S. and S. Quilici, 1991. Trapping studies of citrus greening vector, Diaphorina citri Kuway, natural enemies and alternate hosts in Malaysia. Proceedings of the International Asia Pacific Workshop on Integrated Citrus Health Management, Jun. 24-30, Kuala Lumpur, Malaysia, pp: 118-127. 
Pande, Y.D., 1971. Biology of citrus psylla, Diaphorina citri Kuw. (Hemiptera: Psyllidae). Israel J. Ent., 6: 307-311.

Pruthi, H.S., 1945. Our Knowledge of the Insect and Mite Pests of Citrus in India and their Control. 1st Edn., Indian Council of Agricultural Research, Delhi, pp: 42.

Renwick, J.A.A. and C.D. Radke, 1983. Chemical recognition of host plants for oviposition by the cabbage butterfly, Pieris rapae (Lepidoptera: Pieridae). Environ. Entomol., 12: 446-450.

Tang, L.C. and T.H. Su, 1984. Rearing method and developmental stages of the citrus psylla, Diaphorina citri Kuwayama. Bulletin, Society of Entomology, (National Chungsing University, Taichung, Taiwan), 17: 27-33.

Traynier, R.M.M., 1979. Long-term changes in the oviposition behaviour of the cabbage butterfly, Pieris rapae, induced by contact with plants. Physiol. Entomol., 4: 87-96. DOI: 10.1111/j.13653032.1979.tb00181.x
Tsai, J.H. and Y.H. Liu, 2000. Biology of Diaphorina citri (Homoptera: Psyllidae) on four host plants. J. Econ. Entomol., 93: 1721-1725. DOI: 10.1603/0022-0493-93.6.1721

Waterhouse, D.F., 1998. Biological control of insect pests: Southeast Asian Prospects. 1st Edn., ACIAR, Canberra, ISBN: 1863202218, pp: 548.

Watmough, R.H., 1968. Population studies on two species of Psyllidae (Homoptera, Sternorhyncha) on broom (Sarothamnus scoparius (L.) Wimemr). J. Anim. Ecol., 37: 283-314. DOI: 10.2307/2949

Xu, C.F., Y.H. Xia and C. Ke, 1994. A study on the biology and control of the citrus psylla. Acta Phytophylacica Sinica, 21: 53-56. 